\title{
CARACTERÍSTICAS MICROBIOLÓGICAS DAS MÁOS E ANÉIS DE TRABALHADORES DE SAÚDE - REVISÃO INTEGRATIVA ${ }^{1}$
}

\author{
MICROBIOLOGICAL CHARACTERISTICS OF THE HANDS AND \\ RINGS OF HEALTH WORKERS - INTEGRATIVE REVIEW
}

\section{CARACTERÍSTICAS MICROBIOLÓGICAS DE LAS MANOS Y ANILLOS DE TRABAJADORES DE SALUD - REVISIÓN INTEGRATIVA}

\author{
Isabela FERnANDa Larios Fracarolli* \\ Maria Helena Palucci Marziale**
}

\begin{abstract}
RESUMO
As infecçôes cruzadas na assistência à saúde são reconhecidas como o evento adverso que mais ocorre durante o processo de internação de pacientes em hospitais; assim a adoção de medidas preventivas é legalmente recomendada pela Norma Regulamentadora 32, que estabelece a necessidade de higienização das mãos e a proibição do uso de adornos pelos trabalhadores de saúde, inclusive anéis. Objetivo: Sumarizar as evidências científicas sobre as características microbiológicas das mãos e anéis de trabalhadores de saúde e o risco de infecção cruzada. Material e Método: Revisão integrativa da literatura estruturada nas etapas: questão norteadora, busca, categorização dos estudos, avaliação, interpretaçáo dos resultados e síntese do conhecimento. Foram selecionados artigos originais e revisōes, publicados em inglês, português, espanhol e francês, em revistas indexadas nas principais bases de dados internacionais da área da Saúde, por meio dos descritores aplicados de acordo com as particularidades de cada base de dados e obtidos por consulta nos Descritores de Ciências em Saúde (DeCS) e Medical Subject Headings (MeSH). Resultados: Sete estudos foram analisados e evidenciaram que os principais microrganismos encontrados nas mãos e anéis de profissionais de saúde foram $S$. aureus, Enterococcus spp, $S$. epidermides, Klebsiella spp e E. colli. Conclusão: A contaminação das mãos com e sem anel ocorreu de modo semelhante, não podendo dizer com exatidão se o uso de anéis foi o responsável pelo aumento na quantidade de microrganismos encontrados e se essa prática interfere na infecção cruzada.
\end{abstract}

Palavras-chave: Pessoal de saúde; Bactéria; Infecção hospitalar.

\section{ABSTRACT}

Cross-infections in health care are recognized as being the most frequent adverse event during the hospitalization process of patients. Therefore, the adoption of preventive measures is legally recommended by the Brazilian

${ }^{1} \mathrm{O}$ presente estudo faz parte de projeto financiado pelo Programa Institucional de Bolsas Produtividade em Pesquisa do Conselho Nacional de Desenvolvimento Científico e Tecnológico (CNPq) - Brasil.

*Enfermeira. Doutoranda do Programa Enfermagem Fundamental da Escola de Enfermagem de Ribeirão Preto da Universidade de São Paulo. Ribeirão Preto (SP). Brasil. Email: isabela_larios@hotmail.com - Autor correspondente.

**Enfermeira. Doutora em Enfermagem, Professora Titular da Enfermagem, Escola de Enfermagem de Ribeirão Preto da Universidade de São Paulo. Ribeirão Preto (SP). Brasil. Email: marziale@eerp.usp.br 
Regulatory Standard 32, which establishes the need for hand hygiene and the ban on the use of adornments by health workers, including rings. Objective: To summarize the scientific evidence on the microbiological characteristics of hands and rings of health workers and the risk of cross-infection. Materials and Methods: Integrative review of the literature structured in the following stages: guiding question, search, categorization of studies, evaluation, interpretation of results and synthesis of knowledge. Original articles and reviews published in English, Portuguese, Spanish and French, found in indexed journals of the main international databases of the health area, were selected using applied descriptors for each database and consulting the Health Sciences Descriptors (DeCS) and Medical Subject Headings (MeSH). Results: Seven studies were analyzed and showed that the main microorganisms found in the hands and rings of health professionals were S. aureus, Enterococcus spp, S. epidermides, Klebsiella spp and E. coli. Conclusion: Contamination of hands with and without rings occurred in a similar way. Nevertheless, it cannot be claimed that the use of rings is responsible for the increase in the number of microorganisms found and if this practice interferes in the cross infection.

Key words: Health personnel; Bacteria; Cross-infection.

\section{RESUMEN}

Las infecciones cruzadas en la asistencia a la salud son reconocidas como el evento adverso que más ocurre durante el proceso de internación de pacientes en hospitales. Es por esto que la adopción de medidas preventivas es legalmente recomendada por la Norma Reguladora 32, que establece la necesidad de higienización de las manos y la prohibición del uso de adornos por los trabajadores de salud, incluso anillos. Objetivo: Resumir las evidencias científicas sobre las características microbiológicas de manos y anillos de trabajadores de salud y el riesgo de infección cruzada. Material y Método: Revisión integradora de la literatura estructurada en pasos: pregunta orientadora, búsqueda, categorización de los estudios, evaluación, análisis e interpretación de los resultados y síntesis de los conocimientos. Fueron seleccionados artículos originales y revisiones publicadas en inglés, portugués, español y francés, de acuerdo con las descripciones de las principales bases de datos internacionales del área de la salud, a través de los descriptores aplicados de acuerdo con las particularidades de cada base de datos y obtenidos por consulta en los Descriptores de Ciencias en Salud (DeCS) y Medical Subject Headings (MeSH). Resultados: Siete estudios fueron analizados y evidenciaron que los principales microorganismos encontrados en las manos y anillos de profesionales de salud fueron S. aureus, Enterococcus spp, S. epidermides, Klebsiella spp y E. coli. Conclusión: La contaminación de manos con y sin anillo ocurrió de modo semejante, no pudiendo decir con exactitud si el uso de anillos fue el responsable por el aumento en la cantidad de los microorganismos encontrados y si esa práctica interfiere en la infeción cruzada.

Palabras clave: Personal de salud; Bacterias; Infección hospitalaria.

Fecha recepção: 03/01/2019

Fecha aceitação: 16/04/2019

\section{INTRODUÇÁO}

As Infecçôes Relacionadas à Assistência à Saúde (IRAS) apresentam impacto nas instituiçóes, tanto públicas quanto privadas. Esse problema de saúde global é definido como uma infecção que acomete o paciente durante o processo de internaçáo ou após a alta hospitalar ou unidade de cuidado. A Organização Mundial de Saúde (OMS) transparece preocupação com esse tema ${ }^{(1)}$.
As IRAS são reconhecidas como o evento adverso que mais ocorre durante o processo de internaçáo. Baseado em dados variados, podese perceber que esse problema ocorre em meios gerais, porém apresenta maior destaque em países subdesenvolvidos. Esse fato associa-se, por exemplo, as condiçóes de higiene precárias e infraestrutura inadequada $^{(2)}$. É fato reconhecido que as infecçóes afetam de modo considerável os custos durante a internação, assimilado com a prolongação do 
tempo de internação e maior taxa de morbidade e a mortalidade nos serviços de saúde ${ }^{(3)}$.

Pneumonia, infecção de trato urinário, infecção de corrente sanguínea e infecções cirúrgicas são infecçôes comumente encontradas nos serviços de saúde. A patogênese da pneumonia, por exemplo, engloba o contato entre patógeno, hospedeiro e variáveis epidemiológicas que proporcionam a ocorrência da infecção ${ }^{(3)}$.

Um agravante na ocorrência das IRAS se dá por meio da infecção cruzada entre pacientes, que ocorre principalmente pelas mãos dos trabalhadores de saúde. Preocupados em combater esse problema os órgãos de saúde apresentam estratégias como as Medidas de Prevenção de Infecção que são realizadas de forma a aperfeiçoar o cuidado e evitar a proliferação de microrganismos no ambiente. Dentre as diversas estratégias recomendadas pelos manuais oferecidos, destaca-se, com grande ênfase, a higienização das mãos, bem como a remoção de anéis, relógios e outros adornos presentes durante o contato com o paciente ${ }^{(3)}$. Essa recomendação se deve ao fato de que a transmissão de microrganismos multirresistentes ocorre principalmente através das mãos dos profissionais de saúde. Ao entrarem em contato com o paciente as mãos se tornam progressivamente colonizadas, colaborando como um veículo na disseminação de microrganismos no ambiente hospitalar e na comunidade ${ }^{(4)}$.

Com relação à utilização de adornos por profissionais de saúde, destaca-se que a não remoção desses acessórios no ambiente de trabalho acarreta em aumento na contagem bacteriana nas mãos, perfuração nas luvas de procedimento e contaminação do acessório(5). Embora exista uma recomendação, da parte dos órgãos de saúde, para de remoção dos adornos no ambiente hospitalar, o habito de uso desses acessórios, pelos trabalhadores, ainda é bastante considerável. Um estudo que avaliou a frequência da utilização de joias por trabalhadores de saúde revelou que 43\% dos participantes portavam uma ou várias peças de joalheria no ambiente de trabalho ${ }^{(6)}$.

A maioria dos estudos realizados neste contexto foram direcionados à utilização de anéis, pois acredita-se que eles aumentam a probabilidade de transferência de microrganismos e que o tecido epitelial recoberto pelo anel fique contaminado mesmo após a higienização das mãos. Pesquisadores examinaram vários procedimentos de higienização das mãos e anéis e constataram que quanto mais as mãos com anéis eram higienizadas com uma escova de limpeza sob água corrente, mais bactérias eram removidas $^{(7)}$.

Em estudo que avaliou o uso de diversos agentes no procedimento de higienização das mãos, constatou-se que não houve diferença significativa no número de bactérias entre mãos e mãos sem anéis nos grupos que usaram álcool ou solução álcool-clorexidina. No entanto, para o grupo Iodopovidona, o número de bactérias nas mãos com anéis foi maior quando comparado com mãos sem anéis ${ }^{(8)}$.

No entanto, as evidências científicas resultantes de estudos a respeito do uso de anéis revelaram pouco controle das variáveis, o que coloca em risco a qualidade das informações obtidas. Além disso, as amostras estudadas foram pequenas, algumas pesquisas utilizaram técnicas de coletas sem controle de suas variáveis, não permitindo inferir com exatidão se o anel propiciou maior meio de proliferação de microrganismos ${ }^{(9-11)}$. É preciso considerar a cultura que abrange a utilização de adornos por trabalhadores da saúde e destacar que apesar do uso de joalheria no ambiente de trabalho ser desencorajada pelas instituiçóes e pelos órgãos de saúde, a utilização desses objetos ainda é bastante frequente nas instituiçóes de saúde, incluindo os hospitais $^{(6)}$.

Considerando que muitos profissionais utilizam anéis no ambiente de trabalho e que a prevenção das IRAS é uma prioridade nas instituiçôes de saúde, bem como a manutenção e segurança da integridade de saúde do trabalhador o objetivo dessa pesquisa foi sumarizar as evidências científicas sobre as características microbiológicas de mãos e anéis de trabalhadores de saúde.

\section{MATERIAL E MÉTODO}

Trata-se de uma Revisão Integrativa da Literatura, método que proporciona uma síntese de diversos resultados de diferentes pesquisas sobre a mesma temática, revelando as evidências científicas disponíveis sobre um assunto comum ${ }^{(12)}$.

Uma questão norteadora de pesquisa foi formulada inserindo a identificação de palavras essenciais com o intuito de detectar os estudos primários disponíveis nas bases de dados, sendo ela: 
¿Quais as características microbiológicas das mãos e anéis de trabalhadores de saúde?

Com o objetivo de organizar as estratégias de identificação, seleção e inclusão dos estudos dentro dos critérios de elegibilidade propostos, foi utilizado como base o fluxograma Preferred Reporting Items for Systematic Reviews and Meta-Analyses (PRISMA) (12) que possibilita otimizar o relato de revisóes sistemáticas e meta-análises por meio de um check list com 27 itens e um fluxograma de quatro etapas que norteiam o segmento da revisão.

Como critério de eleição dos estudos incluídos foram selecionados artigos publicados nos últimos 20 anos e disponíveis na íntegra, que abordam características microbiológicas de amostras colhidas de mãos e anéis de trabalhadores de saúde. Os idiomas considerados foram: português, inglês, espanhol e francês.

As bases de dados selecionadas para essa revisão foram: Web of Science (WOS) PubMed, Scopus, EMBASE, Biotechnology and BioEngineering Abstracts, Integrity, Cinhal, Biblioteca Virtual de Saúde (BVS) e Coleção SciELO.

Os descritores e palavras chave utilizados na busca foram aplicados de acordo com particularidades de cada base de dados e obtidos por consulta nos Descritores de Ciências em Saúde (DeCS) e Medical Subject Headings (MeSH). Durante a busca os descritores foram cruzados entre si com o uso do booleano "AND". Os descritores foram inseridos na língua inglesa, pois todas as revistas indexadas nessas bases apresentam em seus artigos descritores em inglês. A busca foi realizada em julho de 2018. O quadro 1 mostra os descritores utilizados nesse estudo, sintetizando a forma como a busca foi realizada.

Ao término do procedimento de busca os artigos originais foram selecionados por meio de leitura de título e resumo. Foram destacados para leitura do artigo na integra aqueles que se apresentaram originais disponíveis nas bases de dados ou na Biblioteca Virtual selecionada, em acesso online aberto, em português, inglês, espanhol ou francês. No procedimento de leitura dos textos completos de cada artigo, foram eleitos os estudos que responderam à pergunta de investigação. Após esse processo, foram excluídas as publicações que não estavam de acordo com os critérios de seleção já mencionados, que não responderam à pergunta de investigação e que estavam em duplicata, bem como, artigos de opiniôes, reflexão teórica, teses, dissertaçóes e capítulo de livro. O processo de seleção dos estudos foi realizado por dupla leitura, em caso de desacordo entre os pesquisadores um terceiro leitor, especialista na temática realizou o desempate. A Figura 1 apresenta o fluxo de informação com as diferentes fases da revisão efetuada. Adaptado do modelo PRISMA ${ }^{(13)}$.

Para a organização dos dados foi utilizado um instrumento adaptado do Formulário da Red de Enfermería em Salud Ocupacional (RedENSO Internacional) ${ }^{(14)}$, utilizado em diversos estudos ${ }^{(14)}$. Os tópicos destacados foram: Título, Ano, Pais, Nível de evidência, Revista, Volume, Base de dados, Idioma, Local, Autor, Amostra, Objetivo, Método de coleta e análise das amostras, Resultados e Conclusão.

Os Níveis de Evidência (NE) considerados

Quadro 1. Descritores utilizados na estratégia de busca dos artigos primários.

\begin{tabular}{ccc}
\hline Base De Datos & Descriptores & $\begin{array}{c}\text { Total Primera } \\
\text { BusCa }\end{array}$ \\
\hline PubMed & Health Personel AND microoganisms AND Jewelry & 13 \\
Cinahl & Health Personel AND microbial contamination AND Jewelry & 4 \\
BVS & Health Personel AND Jewelry & 11 \\
Web of Science & Health Personel AND Jewelry & 9 \\
Scopus & Health Personel AND Jewelry & 53 \\
Biotechnology and & Health Personel AND microbial contamination AND Jewelry & 16 \\
BioEngineering Abstracts & Health Personel AND microbial contamination AND Jewelry & 44 \\
SciELO &
\end{tabular}


nesse estudo foram: nível 1 - estudos com desenho metodológico de meta-análise ou revisóes sistemáticas; nível 2 - ensaios clínicos randomizados controlados; nível 3 - ensaios clínicos sem randomização; nível 4 - estudos de coorte e caso-controle; nível 5 - revisões sistemáticas de estudos descritivos e qualitativos; nível 6 - estudos descritivos ou qualitativos; e nível 7 - opinião de especialistas $^{(15)}$.

Figura 1. Fluxo da seleção dos estudos primários incluídos na revisão sistemática de acordo com as bases de dados selecionadas.

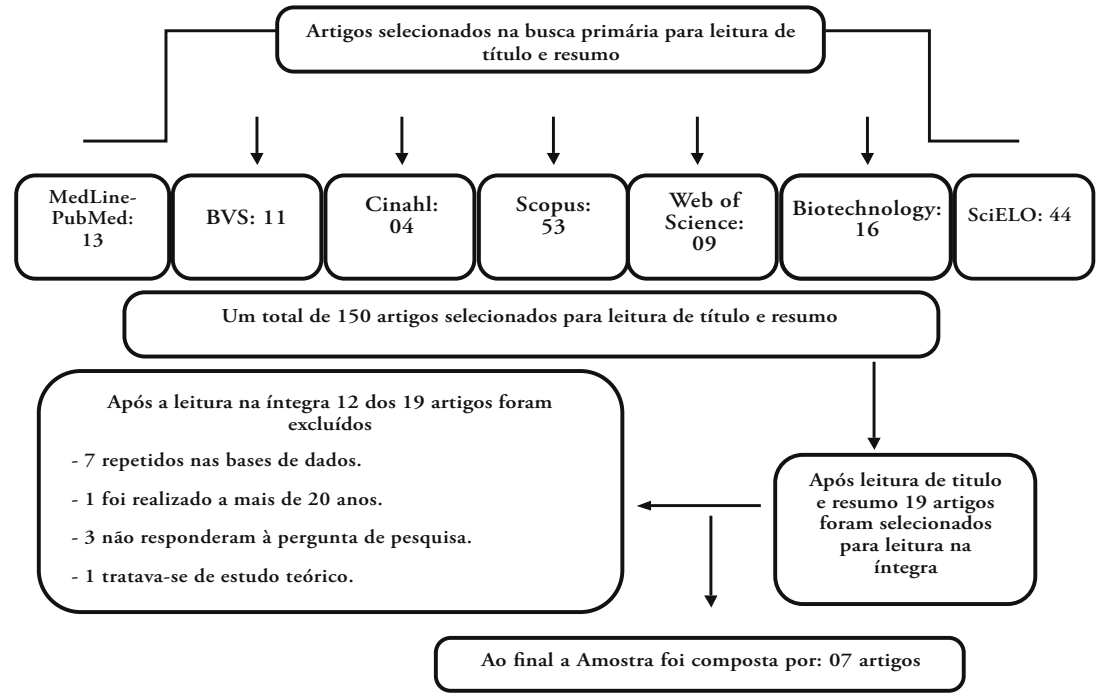

\section{RESULTADOS}

Sete artigos atenderam aos critérios de elegibilidade e responderam à questão de pesquisa dos quais foram caracterizados levando em consideraçáo o título, autores, ano, Nível de Evidência (NE), objetivo e tipo de estudo das publicaçóes incluídas nessa revisão (Quadro 2). Os estudos foram publicados nos anos de $2007^{(9)}, 2008^{(16)}, 2009^{(17)}$, $2011^{(18,19,20)}$ e $2015^{(11)}$. No que diz respeito ao local de realização dos estudos, evidenciou-se que foram desenvolvidos na Noruega ${ }^{(9,17,18)}$, Turquia ${ }^{(16)}$, India ${ }^{(11,20)}$ e Irã $\tilde{a}^{(19)}$.

As pesquisas incluídas nessa revisão avaliaram as características microbiológicas das mãos e anéis de profissionais da saúde. Alguns estudos compararam trabalhadores que utilizavam anéis com um grupo que não os usavam, sendo estes estudos de caso controle considerados de quarto nível de evidência $^{(9,11,16,17)}$. Enquanto estudos transversais, de sexto nível de evidencia, avaliaram somente um grupo $^{(18-20)}$.

Com relação a amostra abordada pelos pesquisadores, tratavam-se de profissionais de saúde de diversas categorias, como médicos ${ }^{(9,18-20)}$,

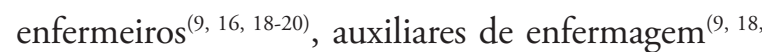
${ }^{19)}$, flebotomistas ${ }^{(9,18)}$, fisioterapeutas ${ }^{(9,18)}$, profissional de radiologia ${ }^{(18)}$, maqueiros ${ }^{(19)}$ e dentistas ${ }^{(11)}$, cujo aspecto comum entre elas é a possibilidade de infecção cruzada.

Para obtenção de culturas de mãos e anéis foram utilizadas técnicas de "suco de luva" (9, 16-18) e Swabs (11, 19, 20).

Após a cultura e análise microbiológica das mãos e anéis dos profissionais de saúde, alguns estudos revelaram que existe maior número de microrganismos nas mãos de profissionais que utilizam anéis quando comparados aos que não utilizam $^{(16,18,21)}$, porém outros estudos revelaram não haver diferença estatística significante quando comparado as mãos com e sem anéis ${ }^{(9,18)}$.

Os microrganismos encontrados nas amostras obtidas foram diversos. Com relação as bactérias detectadas, observou-se que Staphylococcus aureus (S. aureus) apresentou uma predominância de $85 \%$ dos estudos avaliados ${ }^{(9,11,16,18-20)}$. Ainda observando as bactérias gram-positivas detectou-se a presença de Enterococcus $s p p^{(11,16)}$ e Staphylococcus epidermidis ${ }^{(11)}$. Bactérias gram-negativas também foram visualizadas durante análise, com maior 
isolamento de enterobactérias ${ }^{(11,16-20)}$, dentre essas enterobactérias houve uma predominância de Klebsiella $s_{p} p^{(16,19,20)}$ e Escherichia coli ${ }^{(11,16,20)}$.
Algumas pesquisas também detectaram a presença de fungos em suas amostras, com prevalência de Candida albicans ${ }^{(11,19,20)}$.

Quadro 2. Artigos que atendiam aos critérios de elegibilidade.

\begin{tabular}{|c|c|c|c|c|c|}
\hline Titulo & Autores & ANo & $\mathrm{NE}$ & Tipo de Estudo & Овјетіvo \\
\hline $\begin{array}{l}\text { Impact of a Single Plain } \\
\text { Finger Ringi on the } \\
\text { Bacterial Load on the } \\
\text { Hands of Healthcare } \\
\text { Workers. }\end{array}$ & $\begin{array}{l}\text { Mette Fagernes; } \\
\text { Cand.san; Egil } \\
\text { Lingaas; Per Bjark, }\end{array}$ & 2007 & 4 & Caso controle & $\begin{array}{l}\text { Investigar o impacto de um } \\
\text { único anel no número e tipos } \\
\text { de bactérias nas máos dos } \\
\text { profissionais de saúde. }\end{array}$ \\
\hline $\begin{array}{l}\text { A prospective } \\
\text { comparative study of } \\
\text { the relationship between } \\
\text { different types of ring } \\
\text { and microbial hand } \\
\text { colonization among } \\
\text { pediatric intensive care } \\
\text { unit nurses. }\end{array}$ & $\begin{array}{c}\text { Inci Yildirim; } \\
\text { Mehmet Ceyhan; } \\
\text { Ali Bulent Cengiz; } \\
\text { Arzu Bagdatç } \\
\text { Cagri Barin; Tezer } \\
\text { Kutluk; Deniz Gur }\end{array}$ & 2008 & 4 & Caso controle & $\begin{array}{l}\text { Avaliar o efeito do uso de } \\
\text { anéis e tipos de anéis na mão, } \\
\text { contaminação e eficácia de } \\
\text { desinfecção da mão à base de } \\
\text { álcool entre enfermeiros que } \\
\text { trabalham em ambientes de } \\
\text { terapia intensiva. }\end{array}$ \\
\hline $\begin{array}{l}\text { Impact of Finger Rings } \\
\text { on Transmission of } \\
\text { Bacteria During Hand } \\
\text { Contact }\end{array}$ & $\begin{array}{l}\text { Mette Fagernes; } \\
\text { Cand.san; Egil } \\
\text { Lingaas }\end{array}$ & 2009 & 4 & Caso controle & $\begin{array}{l}\text { Investigar o impacto dos anéis } \\
\text { na transmissáo de bactérias das } \\
\text { máos de profissionais de saúde } \\
\text { e impacto sobre a microflora } \\
\text { nas máos dos profissionais de } \\
\text { saúde na prática clínica. }\end{array}$ \\
\hline $\begin{array}{l}\text { Factors interfering } \\
\text { with the microflora } \\
\text { on hands: a regression } \\
\text { analysis of samples from } \\
465 \text { healthcare workers }\end{array}$ & $\begin{array}{l}\text { Mette Fagernes; } \\
\text { Egil Lingaa }\end{array}$ & 2011 & 6 & Transversal & $\begin{array}{l}\text { Verificar o impacto de anéis, } \\
\text { relógios, unha postiça, } \\
\text { comprimento das unhas, } \\
\text { loção para as mãos e gênero na } \\
\text { microbiologia das mãos dos } \\
\text { profissionais de saúde. }\end{array}$ \\
\hline $\begin{array}{l}\text { Bacterial colonization } \\
\text { of rings and cell phones } \\
\text { carried by health-care } \\
\text { providers: are these } \\
\text { mobile bacterial zoos in } \\
\text { the hospital? }\end{array}$ & $\begin{array}{c}\text { Sonal Saxena; } \\
\text { Geeta Mehtaç Renu } \\
\text { Dutta }\end{array}$ & 2011 & 6 & Transversal & $\begin{array}{l}\text { Avaliar a presença de registros } \\
\text { de organismos patogênicos nos } \\
\text { anéis e celulares transportados } \\
\text { por trabalhadores da saúde. }\end{array}$ \\
\hline $\begin{array}{l}\text { Evaluation of } \\
\text { bacterial and fungal } \\
\text { contamination in the } \\
\text { health care workers' } \\
\text { hands and rings in the } \\
\text { intensive care unit. }\end{array}$ & $\begin{array}{l}\text { S. Khodavais; M. } \\
\text { Nabili; B. Davari; } \\
\text { M. Vahedi }\end{array}$ & 2011 & 6 & Transversal & $\begin{array}{c}\text { Determinar a taxa de } \\
\text { contaminaçáo (bacteriana } \\
\text { e fúngica) das máos dos } \\
\text { trabalhadores da saúde e do } \\
\text { anel na UTI. }\end{array}$ \\
\hline $\begin{array}{l}\text { Contamination of } \\
\text { Dentist's Hands with } \\
\text { and without Finger } \\
\text { Rings. }\end{array}$ & $\begin{array}{c}\text { Ahmad Naeem; } \\
\text { Sachdev Arti } \\
\text { Saluja; Deo } \\
\text { Krishna; Malhotra } \\
\text { Shitanshu; Sachdev } \\
\text { Arun; Bashir Taseer }\end{array}$ & 2015 & 4 & Caso controle & $\begin{array}{l}\text { Investigar ocorrência de } \\
\text { potenciais bactérias patogênicas } \\
\text { e fungos na pele de mãos } \\
\text { enluvadas de trabalhadores de } \\
\text { saúde bucal que usavam anéis e } \\
\text { comparar com aqueles que náo } \\
\text { usavam anéis sob luvas. }\end{array}$ \\
\hline
\end{tabular}




\section{DISCUSSÃO}

Os estudos analisados nessa revisão apresentam abordagem metodológica similar. $\mathrm{Na}$ análise microbiológica das mãos e anéis de profissionais da saúde, constatou-se que grande parte das pesquisa selecionaram amostras de profissionais de saúde específicos, em que as principais categorias profissionais estudadas foram médicos, enfermeiros e técnicos de enfermagem, possivelmente por estarem diretamente, e por maior período, em contato com os pacientes durante a prestação da assistência de saúde e por isso considerados os principais agentes de transmissão de microrganismo no ambiente de saúde.

Alguns estudos foram direcionados a detecção de microrganismos nas mãos, narinas, jalecos e acessórios desses profissionais ${ }^{(22-24)}$. Um estudo recente, que avaliou a taxa de colonização dos aparelhos celulares de trabalhadores de uma unidade de terapia intensiva, antes e após o turno de trabalho, constatou que todos os telefones celulares dos trabalhadores da unidade estavam colonizados por microrganismos, mesmo antes do turno de trabalho e independentemente da microbiota dos pacientes. Os microrganismos mais comuns foram Estafilococos Coagulase-Negativos, Bacillus spp. e Staphylococcus aureus resistente à Meticilina (MRSA) ${ }^{(25)}$.

Atentando para os procedimentos microbiológicos é importante levar em consideração as técnicas abordadas para coleta de material microbiológico nas pesquisas analisadas. A técnica de "suco de luvas", que prevalece nesses estudos, consiste na inserção da mão em uma luva ou saco estéril contendo um meio nutritivo específico, a mão é massageada por um tempo determinado e logo após é realizada a análise microbiológica do caldo proposto. Trata-se de uma técnica bastante utilizada por pesquisadores que desejam obter resultados de amostras das mãos ${ }^{(26)}$. As demais pesquisas utilizam a técnica de coleta por meio de swabs, outro método comum para estudos em microbiologia ${ }^{(24,27)}$.

Com relação aos microrganismos predominantes encontrados nos estudos, percebe-se que $S$. aureus aparece com grande ênfase nas amostras obtidas. Esses microrganismos são, com frequência, encontrados no ambiente hospitalar e também são considerados comuns napele da população. Contudo é indispensável associar esses microrganismos como agentes causadores de infecção nosocomial ${ }^{(28)}$. Pesquisadores determinaram a taxa de portadores nasais de MRSA comparando os perfis de suscetibilidade antimicrobiana de Staphylococcus aureus sensíveis à Meticilina (MSSA) em um Pronto Socorro PS de Hospital Universitário da Unganda; esse estudo demonstrou uma alta taxa de portadores nasais de $S$. aureus $(28,8 \%)$, dos quais $46 \%$ eram fenotipicamente MRSA e 28,6\% genotipicamente MRSA $^{(29)}$.

Ainda dentre os microrganismos isolados nas pesquisas inseridas na revisão, deve-se atentar para a presença de enterobactérias, também muito comuns no ambiente hospitalar. Estudos recentes demonstram a presença de bactérias gram-negativas colonizando profissionais de saúde, dentre elas incluem-se enterobactérias multirresistentes aos antimicrobianos $^{(30,31)}$.

No que diz respeito à presença de fungos encontrados nas mãos e anéis de trabalhadores é importante considerar que evidências apontam para a presença de fungos como Candida glabrata colonizando máos e aventais de trabalhadores de saúde ${ }^{(32)}$. Embora Candida parapsilosis e Candida glabrata apresentem menos fatores de virulência dentre as espécies não albicans, ainda apresentam maior taxa de mortalidade do que a mesma. A presença de Candida albicans apresenta predominância nessa revisão, nesse cenário, Rosenthal ${ }^{(33)}$ revela a presença comum desse fungo contaminando as mãos de trabalhadores de uma Unidade de Terapia Intensiva.

Nesse aspecto é comprovado que a higiene das mãos reduz consideravelmente a quantidade tanto bactérias como fungos. Embora a adesão a essa prática ainda seja baixa ${ }^{(34,35)}$. No Brasil, um estudo realizado em Unidades de Terapia Intensiva constatou que a taxa de adesão às práticas de higienização das mãos foi maior entre profissionais da enfermagem e fisioterapeutas e menor entre os técnicos de enfermagem ${ }^{(36)}$.

No que diz respeito à limitação deste estudo, considera-se que o número de artigos inseridos é inferior ao esperado, isso pode estar associado ao fato de que essa pesquisa utilizou apenas dados primários durante a busca e nesse caso a análise pode apresentar certa subjetividade. Por outro lado, os resultados desta pesquisa possibilitam o aprofundamento de novos estudos a partir de 
variáveis identificadas principalmente no que se refere a robustez metodológica e o tipo agentes microbiológicos.

\section{CONCLUSÃO}

Por meio desta revisão foi possível concluir que os principais microrganismos encontrados nas mãos e anéis de trabalhadores de saúde foram bactérias gram positivas como $S$. aureus, Enterococcus spp e $S$. epidermides, seguidos por bactérias gram negativas como Klebsiella spp e E. colli. Fungos também foram detectados com predominância de cândida

\section{REFERÊNCIAS}

1. WHO. World Health Organization. Guidelines on Hand Hygiene in Health Care: First Global Patient Safety Challenge Clean Care Is Safer Care. World Health [Internet]. Switzerland, 2009 [citado 2018 May 7]; 270 p. Disponível em: http://whqlibdoc. who.int/publications/2009/9789241597906_eng. pdf.

2. Allegranzi B, Bagheri S, Combescure C, Graafmans W, Attar H, Donaldson L, et al. Burden of endemic health-care-associated infection in developing countries: systematic review and meta-analysis. Lancet [Internet]. 2011 Jan 15 [citado 2018 May 22]; 377(9761): 228-41. Disponível em: https:// www.thelancet.com/journals/lancet/article/ PIIS0140-6736(10)61458-4/fulltext.

3. Agência Nacional de Vigilância Sanitária. Medidas de Prevenção de Infecção Relacionada à Assistência à Saúde 4 [Internet]. Brasil, 2017 [citado 2018 May 7]; 122 p. Disponível em: http://portal.anvisa.gov. br/documents/33852/3507912/Caderno+4+-+Me didas+de+Prevenção+de+Infecçâo+Relacionada+à +Assistência+à+Saúde/a3f23dfb-2c54-4e64-881cfccf9220c373.

4. Horan TC, Andrus M, Dudeck MA. CDC/NHSN surveillance definition of health care-associated infection and criteria for specific types of infections in the acute care setting. Am J Infect Control [Internet]. 2008 Jun [citado 2018 May 22]; 36(5): 309-32. Disponível em: http://www.ncbi.nlm.nih. gov/pubmed/18538699.

5. Ward DJ. Hand adornment and infection control. Br J Nurs [Internet]. 2013 Sept [citado 2018 albicans. É importante conhecer a contaminação presente nas mãos e anéis dos profissionais que atuam no contato direto com o paciente. Desse modo não foi possível constatar com exatidão se o uso de anéis foi o responsável pelo aumento na quantidade dos microrganismos presentes nas mãos dos profissionais de saúde. Assim, novas pesquisas são necessárias para que melhores barreiras possam ser estabelecidas para evitar infecçóes cruzadas e para apoiar, com maior evidência, as políticas de segurança e as normas legais de proteção e segurança ocupacional para os profissionais de saúde expostos a microrganismos.

Jun 14], 16(11): 654-6. Disponível em: https:// www.magonlinelibrary.com/doi/pdf/10.12968/ bjon.2007.16.11.23677.

6. Vandenbos F, Gal J, Dandine M, Six C, Veyres P, Chappuis V, et al. Évaluation du port de bijou chez des professionnels de la santé français. Médecine Mal Infect [Internet]. 2011 Apr [citado 2018 May 7]; 41(4): 192-96. Disponível em: https://www.sciencedirect.com/science/article/pii/ S0399077X10003422?via\%3Dihub.

7. Alur AA, Rane MJ, ScheetzJP, Lorenz DJ, Gettleman L. Simulated microbe removal around finger rings using different hand sanitation methods. Int J Oral Sci [Internet]. 2009 Aug 24 [citado 2017 Aug 31]; 1(3): 136-42. Disponível em: http://www.ncbi. nlm.nih.gov/pubmed/20695078.

8. Wongworawat MD, Jones SG. Influence of rings on the efficacy of hand sanitization and residual bacterial contamination. Infect. Control hosp. Epidemiol. [Internet]. 2007 Mar [citado 2019 sep 26]; 28(3): 351-3. Disponível em: https://www. ncbi.nlm.nih.gov/pubmed/17326029.

9. Fagernes M, Lingaas E, Bjark P. Impact of a Single Plain Finger Ring on the Bacterial Load on the Hands of Healthcare Workers. Infect Control Hosp Epidemiol [Internet]. 2007 Oct [citado 2018 May 22]; 28(10): 1191-95. Disponível em: https:// www.cambridge.org/core/journals/infectioncontrol-and-hospital-epidemiology/article/impactof-a-single-plain-finger-ring-on-the-bacterialload-on-the-hands-of-healthcare-workers/ CA6C84571952718877DB58704A22D5A5.

10. Salisbury DM, Hutfilz P, Treen LM, Bollin GE, Gautam S. The effect of rings on microbial 
load of health care workers' hands. Am J Infect Control [Internet]. 1997 Feb [citado 2017 Aug 31]; 25(1): 24-27. Disponível em: https://www. ncbi.nlm.nih.gov/pubmed/9057940.

11. Naeem A, Saluja SA, Krishna D, Shitanshu M, Arun S, Taseer B. Contamination of Dentist's Hands with and without Finger Rings. J Int oral Health [Internet]. 2015 May 16 [citado 2017 Aug 31]; 7(8): 114-17. Disponível em: https://www. ncbi.nlm.nih.gov/pmc/articles/PMC4588775/.

12. Mendes KDS, Pereira RC, Galvão CM. Revisão integrativa: método de pesquisa para a incorporação de evidências na saúde e na enfermagem. OutDez [Internet]. 2008 Oct 8 [citado 2017 Sep 26]; 17(4): 758-64. Disponível em: http://www.scielo.br/scielo.php?script=sci_ arttext\&pid=S0104-07072008000400018.

13. Galvão TF, Andrade TS, Harrad D. Principais itens para relatar revisões sistemáticas e metaanálises: A recomendação PRISMA. Epidemiol e Serviços Saúde [Internet]. 2015 Jun [citado 2018 May 10]; 24(2): 335-42. Disponível em: http://www.scielo.br/scielo.php?script=sci_ arttext\&pid=S2237-96222015000200335.

14. Marziale MHP. Instrumento para recolección de datos, revisión integrativa [Internet]. 2017 [citado 2019 Aug 13]. RedENSO. Disponível em: http:// gruposdepesquisa.eerp.usp.br/sites/redenso/wpcontent/uploads/sites/9/2019/09/Instrumiento_ revision_litetarura_RedENSO_2015.pdf.

15. Melnyk BM, Fincout-Overholt E. Making the case for evidence-based practice. In: Melnyk BM, Fincout-Overholt E. (Eds.). Evidence-based practice in nursing and healthcare: A guide to best practice. $1^{\text {a }}$ ed. Philadelphia: Lippincott Williams \& Wilkins; 2005. pp. 3-24.

16. Yildirim I, Ceyhan M, Cengiz AB, Bagdat A, Barin C, Kutluk T, et al. A prospective comparative study of the relationship between different types of ring and microbial hand colonization among pediatric intensive care unit nurses. Int J Nurs Stud. 2008; 45(11): 1572-6.

17. Fagernes M, Lingaas E. Impact of Finger Rings on Transmission of Bacteria During Hand Contact. Infect Control Hosp Epidemiol [Internet]. 2009 [citado 2018 Aug 18]; 30(05): 427-432. Disponível em: https://www.cambridge.org/core/ product/identifier/S0195941700036766/type/ journal_article.

18. Fagernes M, Lingaas E. Factors interfering with the microflora on hands: a regression analysis of samples from 465 healthcare workers. J Adv Nurs [Internet]. 2011 Feb [citado 2017 Aug 31]; 67(2): 297-307. Disponível em: https://onlinelibrary.wiley.com/ doi/abs/10.1111/j.1365-2648.2010.05462.x.
19. Khodavaisy S, Nabili M, Davari B, Vahedi M. Evaluation of bacterial and fungal contamination in the health care workers' hands and rings in the intensive care unit. J Prev Med Hyg [Internet]. 2011 Dec [citado 2017 Oct 9]; 52(4): 215-18. Disponível em: http://www.ncbi.nlm.nih.gov/ pubmed/22442928.

20. Saxena S, Singh T, Agarwal H, Mehta G, Dutta $\mathrm{R}$. Bacterial colonization of rings and cell phones carried by health-care providers: Are these mobile bacterial zoos in the hospital? Trop Doct. 2011; 41(2): 116-8.

21. Mahmoud AM, Albadawy HS, Bolis SM, Bilal NE, Ahmed AO, Ibrahim ME. Inducible clindamycin resistance and nasal carriage rates of staphylococcus aureus among healthcare workers and community members. Afr Health Sci. 2015; 15(3): 861-7.

22. Ahamed M., Elramalli A., Amri S., Abuzweda A. Isolation and screening of methicillin-resistant Staphylococcus aureus from health care workers in libyan hospitals. East Mediterr Heal J [Internet]. 2012; 18(1): 37-42. Disponível em: https://www. ncbi.nlm.nih.gov/pubmed/22360009.

23. De Oliveira A, Medeiros M. Jalecos de trabalhadores de saúde: um potencial reservatório de microrganismos. Medicina (Ribeirão Preto). 2015; 48(5): 440-8.

24. Castro A, Komora N, Ferreira V, Lira A, Mota M, Silva J, et al. Prevalence of Staphylococcus aureus from nares and hands on health care professionals in a Portuguese Hospital. J Appl Microbiol. 2016; 121(3): 831-9.

25. Galazzi A, Panigada M, Broggi E, Grancini A, Adamini I, Binda F, et al. Microbiological colonization of healthcare workers' mobile phones in a tertiary-level Italian intensive care unit. Intensive Crit Care Nurs [Internet]. 2019 Jun 1 [citado 2019 Apr 27]; 52: 17-21. Disponível em: https:/www.sciencedirect.com/science/article/abs/ pii/S0964339718303227?via\%3Dihub.

26. Waterman TR, Smeak DD, Kowalski J, Hade EM. Comparison of bacterial counts in glove juice of surgeons wearing smooth band rings versus those without rings. Am J Infect Control [Internet]. 2006 Sep [citado 2017 Sep 8]; 34(7): 421-5. Disponível em: http://linkinghub.elsevier.com/retrieve/pii/ S0196655306000800.

27. Valadares B Dos S, Barbosa RM, Teixeira RAV, De Oliveira RA, Tomich GM. Contaminação de uniformes privativos utilizados por profissonais que atuam nas unidades de terapia intensiva. Rev Epidemiol e Control Infecção [Internet]. 2017 Jan 5 [citado 2018 May 22]; 7(1): 1-11. Disponível em: https://online.unisc.br/seer/index.php/epidemiologia/ article/view/7380/5593. 
28. Harris $\mathrm{AD}$, Samore $\mathrm{MH}$, Nafziger R, DiRosario K, Roghmann MC, Carmeli Y. A survey on handwashing practices and opinions of healthcare workers. J Hosp Infect [Internet]. 2000 Aug 1 [citado 2018 Jun 12]; 45(4): 318-21. Disponível em: https://www.sciencedirect.com/science/article/ pii/S0195670100907813.

29. Abimana JB, Kato CD, Bazira J. MethicillinResistant Staphylococcus aureus Nasal Colonization among Healthcare Workers at Kampala International University Teaching Hospital, Southwestern Uganda. Can J Infect Dis Med Microbiol [Internet]. 2019 Mar 10 [citado 2019 Apr 27]; 2019: 1-7. Disponível em: https://www. hindawi.com/journals/cjidmm/2019/4157869/.

30. Tselebonis A, Nena E, Nikolaidis C, Konstantinidis T, Kontogiorgis C, Panopoulou M, et al. Monitoring of Frequency and Antimicrobial Susceptibility of Pathogens on the Hands of Healthcare Workers in a Tertiary Hospital. Folia Med (Plovdiv) [Internet]. 2016 Sep 30 [citado 2018 May 11]; 58(3): 2005. Disponível em: http://www.ncbi.nlm.nih.gov/ pubmed/27760007.

31. Leão VLS de $\mathrm{O}$, Lima $\mathrm{ABM}$, Costa $\mathrm{D}$ de $\mathrm{M}$, Rocha VLO, Oliveira ACA, Gonçalves NF, et al. Enterobacteriaceae isolates from the oral cavity of workers in a brazilian oncology hospital. Rev Inst Med Trop Sao Paulo. 2015; 57(2): 121-7.

32. Savastano C, De Oliveira E, Gonçalves LL, Nery JM, Silva NC, Dias ALT. Candida glabrata among Candida spp. from environmental health practitioners of a Brazilian Hospital. Brazilian J Microbiol [Internet]. 2016 Mar 2 [citado 2018 Jun 14]; 47(2): 367-72. Disponível em: http://www. ncbi.nlm.nih.gov/pubmed/26991302.

33. Rosenthal M, Aiello A, Larson E, Chenoweth C, Foxman B. Healthcare Workers' Hand Microbiome May Mediate Carriage of Hospital. Pathogens [Internet]. 2013 Dec 27 [citado 2018 Jun 14]; 3(1): 1-13. Disponível em: http://www.mdpi. com/2076-0817/3/1/1.

34. Brühwasser C, Hinterberger G, Mutschlechner W, Kaltseis J, Lass-Flörl C, Mayr A. A point prevalence survey on hand hygiene, with a special focus on Candida species. Am J Infect Control [Internet]. 2016 Jan 1 [citado 2018 Jun 14]; 44(1): 71-3. Disponível em: http://www.ncbi.nlm.nih. gov/pubmed/26320699.

35. Pinheiro EC, Da Silva FL. Conhecimento e adesão da prática de higienização das mãos dos profissionais da saúde: revisão bibliográfica. Saúde em Foco [Internet]. 2016 Jun [citado 2018 Jun 14]; 3(1): 8493. Disponível em: http://189.43.21.151/revista/ index.php/saudeemfoco/article/view/742/1001.

36. Silva AL, Reis LC, Marinho Couto BR, Ferreira CE, Vaz R. Avaliação das práticas de higienização das mãos em três unidades de terapia intensiva. Rev Epidemiol Controle Infecç [Internet]. 2019 Jan 17 [citado 2019 Apr 27]; 9(1) 55-9. Disponível em: https://online. unisc.br/seer/index.php/epidemiologia/article/ view/11605/7911. 